\title{
Green approach for the activation and functionalization of jute fibers through ball milling
}

\author{
Rocio Gallego • Carmen C. Piras - Laurens A. J. Rutgeerts - Susana Fernandez-Prieto • \\ Wim M. De Borggraeve $\cdot$ Jose M. Franco $\cdot$ Johan Smets
}

\begin{abstract}
As well known, cellulose fibers, defibrillated/activated in different degrees or even chemically modified, can be employed as additives in matrixes of different nature with the aim of modulating some properties such as the mechanical resistance, rheological behavior or hydrophobicity of the product. Consequently, there is an increasing interest in the incorporation of these materials in a wide variety of products, being necessary the development of green methodologies for their chemical modification. The objective of this work is the use of the ball milling technology as tool for the activation and chemical modification of cellulose fibers, specifically of cellulosic material from jute. The traditional method used to date for the NCO-functionalization of cellulose
\end{abstract}

R. Gallego $(\bowtie) \cdot$ J. M. Franco

Department of Chemical Engineering, University of Huelva, Campus El Carmen, Campus ceiA3,

21071 Huelva, Spain

e-mail: rocio.gallego@diq.uhu.es

C. C. Piras - L. A. J. Rutgeerts - W. M. De Borggraeve Department of Chemistry, KU Leuven, 3001 Leuven, Belgium

S. Fernandez-Prieto $\cdot$ J. Smets

Brussels Innovation Center, Procter and Gamble Services Company NV, 1853 Strombeek Bever, Belgium

J. M. Franco

Pro2TecS-Chemical Process and Product Technology Research Center, University of Huelva, 21071 Huelva, Spain fibers requires a solvent as reaction medium, the action of a catalyst and a previous stage of mercerization to boost the reactivity of the fibers. Accordingly to the former, jute fibers were NCO-functionalized, on one side, evading previous mercerization and, on other side, applying two different alkali-based activation pre-treatments that lead to materials with different crystallinity index. In addition to this, and after having optimized milling conditions, both activation and NCO-functionalization were successfully carried out in a planetary ball mill avoiding solvent, catalyst and previous alkalization. Cellulose fibers esterification was successfully implemented over already ball milled cellulosic material, showing that activation and chemical modification do not need to be performed at the same time. Fourier transform infrared spectroscopy provided the follow-up of each reaction and the impact of ball milling on the fibers was analyzed by hydrodynamic diameter measurements. Thus, it is demonstrated that ball milling can be proposed as an efficient and environmentally friendly methodology for the activation and/or functionalization of cellulose fibers. 


\section{Graphic abstract}

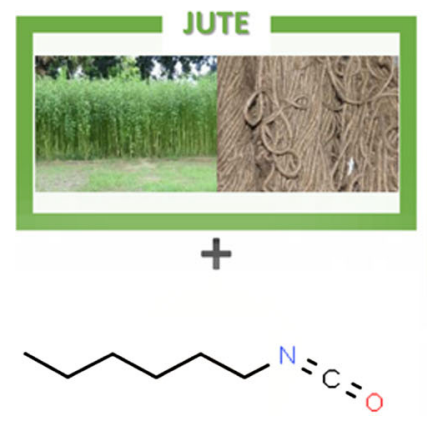

Keywords Cellulose $\cdot$ Jute fibers $\cdot$ Ball milling · Isocyanate

\section{Introduction}

Lignocellulosic fibers, abundant and environmentally friendly, are being extensively developed nowadays and can be found in many new products. They are applicable in a wide variety of fields, i.e. as components for electronic and energy devices (Dutta et al. 2017), membranes and filters for water purification (Voisin et al. 2017) or adhesive replacement in fiberboards (Diop et al. 2017). This is due to the numerous advantages they offer such as cost-effectiveness, biodegradability, specific mechanical properties, processing flexibility and the possibility of modulating their properties through surface treatments (Arrakhiz et al. 2012; Ghali et al. 2011; López Durán et al. 2018). As consequence, a rational use of nonwood fibers has become increasingly noteworthy for the protection of the environment, further leading to additional support by government regulations in some countries. In this sense, jute is a cheap multicellular non-wood fiber that is broadly cultivated in Asian countries such as China, India and Bangladesh. It shows a very high crystallinity index (CI) compared to other non-woods fibers (Cao et al. 2012) and also has a high content of cellulose $(71.5 \%)$ together with hemicellulose $(13.3 \%)$ and relatively low non-cellulosic components like lignin, pectin and vegetable wax (Yu et al. 2014).

Each fiber consists of rigid cellulose microfibrils that are embedded in a soft matrix mainly composed of lignin, which plays important roles such as water
NCO-functionalized

ball milled jute fibers

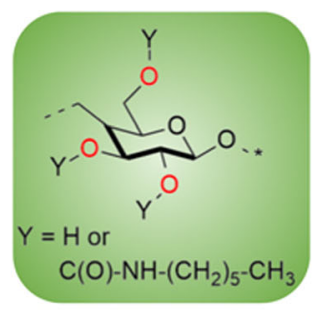

holding, protection against biochemical stress or addition of strength and structure; and hemicellulose, which coordinates cellulose together with lignin (Boerjan et al. 2003; Hansen and Björkman 1998; Panshin and De Zeeuw 1980). Cellulose, as the main constituent of plant cell walls, provides the structural support. It consists of $\beta-\mathrm{D}$-glucopyranose sugar units, which contain three hydroxyl groups at the C-2, C-3 and C-6 positions. They can form strong hydrogen bonds, constituting the crystalline and amorphous regions within the fibers, which interact with each other to form cellulose microfibrils. Cellulose is known to exist in different polymorphs depending on the molecular orientation and hydrogen-bonding network in crystalline domains. The four main polymorphs of cellulose are cellulose I, cellulose II, cellulose III and cellulose IV. The most extensively investigated are cellulose I, which is the dominant form in natural wood and plants, and cellulose II that can be obtained from cellulose I either by chemical regeneration or mercerization, due to its relatively low thermal stability. Cellulose I, present in native cellulose, exists as cellulose I $\alpha$ (triclinic unit cell) and cellulose I $\beta$ (monoclinic unit cell), both with cellulose chains adopting parallel configurations. In contrast, the chains of cellulose II are in an antiparallel configuration and exist in a monoclinic unit cell (Gong et al. 2017). Despite cellulose I exhibits much better mechanical properties than cellulose II (O'Sullivan 1997; Yu et al. 2014), the later has a more stable structure, making it preferable for various applications.

Cellulose can be submitted to a wide variety of chemical modifications due to the three hydroxyl groups present in its structure. Furthermore, reactivity of cellulose can be enhanced through previous 
mercerization. This alkali treatment, which causes the removal of lignin and hemicellulose (Kim and Netravali 2010), acts easing the accessibility of hydroxyl groups, increasing the inner surface, altering crystallinity and breaking hydrogen bonds (Ray et al. 2001). On the other hand, the hydrophilic nature of cellulose fibers derived from the hydroxyl groups results in poor compatibility with hydrophobic media, restricting its field of application. Chemical modification has been used for ages as a tool to decrease the number of reactive hydroxyl groups of cellulose (Gallego et al. 2015; Paquet et al. 2010; Torres and Cubillas 2005; Zhang et al. 2010), being the reaction with isocyanates a common tool (Gallego et al. 2013a; Huang and Wang 2017; Suwanruji et al. 2017; Tenorio-Alfonso et al. 2017; Tonoli et al. 2013). Additionally, if the functional groups inserted in cellulose fibers are not only hydrophobic but also voluminous, the energy required for fiber defibrillation may get lower as well as a result of steric hindrance.

Amongst all the methods that can be employed for the activation and chemical modification of jute fibers, ball milling is a promising green technology that is gaining more interest (M'Hamed 2015; Piras et al. 2019; Stolle et al. 2011, 2013; Stolle 2015; Takacs 2002). This technique is commonly used to grind powders and blend materials (Moosakazemi et al. 2017). The instrument consists of a hollow cylindrical shell rotating around its axis. It is partially filled with balls which act as grinding or milling medium. One of the most common types of ball mill is the planetary mill, in which the vessels are placed on a rotating supporting disk and rotate around their own axes (Gorrasi and Sorrentino 2015). The entire process is based on the energy released from impact and attrition between the balls and the powder. This method can be applied in wet and dry conditions on a wide range of materials (e.g. chemicals, fibers, polymers, hydroxyapatite, metal oxides, pigments, catalysts) and has the advantages of being cost-effective, easy to use and reproducible. However, it has to be noted that this method has a high impact on the properties of the resulting material after treatment, including morphological and structural features, crystallinity and thermal stability. This has been largely demonstrated in the case of cellulose fibers. When dry conditions are applied, usually a decrease in the degree of crystallinity and variations in polymorphism are observed (Ago et al. 2004, 2007; Khan et al. 2016; Nemoto et al.
2017). The thermal degradation profile can also vary after milling, with a decrease in the thermal degradation temperature (Hideno 2016).

Products from different fields, such as cosmetics or consumer goods, require the adequate rheological behavior to properly accomplish their mission and to provide consumer satisfaction. Defibrillated or activated cellulose fibers can play the role of ecological and cheap rheological modifiers in this kind of products; however, in many cases, the intrinsic cellulose hydrophilicity is incompatible with the rest of ingredients. The main goal of this research is to exploit the ball mill technology for the activation and chemical functionalization of cellulose jute fibers in a fast, environmentally friendly and cost-effective way. In particular, it is focused on increasing the hydrophobicity of the fibers by inserting -NCO functionalities and ester groups. We herein demonstrate that the ball mill technology can be used to NCO-functionalize cellulose fibers without the need of a solvent and a catalyst. To the best of our knowledge, this is the first time that this technology is employed for this type of reaction on cellulose jute fibers. Compared to the traditional methods described in literature it has the advantage of being easy, quick, and economical and allows avoiding the use of organic solvents.

\section{Materials and methods}

Materials

Cellulose jute fibers were supplied by Celesa as bleached sheets. These were cut in small pieces with scissors and ground, first with a kitchen grinder and then with a common coffee grinder. All reagents and solvents were supplied by Sigma-Aldrich and Acros.

\section{Mercerization process}

The alkalization of cellulose fibers was carried out as described by Yu et al. (2014). Ground cellulose fibers were dispersed in hot $\mathrm{NaOH}$ aqueous solution up to get to 1:60 material to liquid (w/w) ratio. After stirring for $4 \mathrm{~h}$, mercerized cellulose fibers were washed multiple times with deionized water using a centrifuge. With the aim of producing cellulose fibers with lower and higher CI respecting the starting material, two different conditions were applied for the alkalization: 
$15 \mathrm{wt} \% \mathrm{NaOH}$ solution at $85{ }^{\circ} \mathrm{C}$ (JF-A15) and $8 \mathrm{wt} \%$ $\mathrm{NaOH}$ solution at $70{ }^{\circ} \mathrm{C}$ (JF-A8), respectively. The products were stored at $4{ }^{\circ} \mathrm{C}$.

NCO-functionalization reaction by the traditional method

Cellulose fibers were reacted with hexyl isocyanate following the procedure reported by Gallego et al. (2013a). Cellulose fibers $(5.00 \mathrm{~g})$ were dispersed in toluene $(300 \mathrm{~mL})$ and the system was deoxygenated passing Argon through it for $30 \mathrm{~min}$. Triethylamine $(0.94 \mathrm{~g}, 1.86 \mathrm{mmol} / \mathrm{g}$ cellulose) and hexyl isocyanate ( $0.61 \mathrm{~g}, 0.93 \mathrm{mmol} / \mathrm{g}$ cellulose) were then added in this order while stirring vigorously. The reaction was conducted at room temperature under inert atmosphere for $24 \mathrm{~h}$. Subsequently, the excess of toluene was removed by decantation and a solvent exchange was carried out to obtain the NCO-functionalized jute fibers as slurry in water. Fibers were first washed 5 times with ethanol and then 5 times with water, using the centrifuge. The product was stored at $4{ }^{\circ} \mathrm{C}$. For the mercerized jute fibers used as starting material for the NCO-functionalization (JF-A15 and JF-A8), a solvent exchange from water to toluene was required prior to performing the reaction. The proportion of reagents employed was that required to achieve a degree of functionalization of approximately 5\% (samples JFFC, JF-A15-FC and JF-A8-FC).

Ball milling

Ball milling was performed using a Planetary Micro Mill, PULVERISETTE 7 premium line, Fritsch. Two zirconium oxide chambers ( $80 \mathrm{~mL}$ volume) were filled with 25 zirconium oxide milling balls $(10 \mathrm{~mm}$ diameter), resulting in a filling ratio of $32 \%$, and ground jute fibers ( $1 \mathrm{~g}$ in each chamber) (JF-B). The process was carried out at room temperature and at different rotational speeds and times.

NCO-functionalization reaction by ball milling

The NCO-functionalization of jute fibers by ball milling was carried out at a rotational speed of $800 \mathrm{rpm}$ for $2 \mathrm{~min}$ and at room temperature. Jute fibers $(1 \mathrm{~g})$ and hexyl isocyanate $(0.14 \mathrm{~mL}$, $0.93 \mathrm{mmol} / \mathrm{g}$ cellulose) were added in this order to the initially ground fibers (JF-B1-F) and to fibers that were not only ground but also ball milled for $2 \mathrm{~min}$ at $800 \mathrm{rpm}$ prior to the chemical reaction (JF-B2-F). Additionally, the effect of a catalyst was tested by the addition of triethylamine $(0.12 \mathrm{~mL}, 0.86 \mathrm{mmol} / \mathrm{g}$ cellulose) resulting the samples JF-B1-FC and JFB2-FC. The formation of the urethane linkage was confirmed through Fourier transform infrared spectroscopy (FTIR) spectroscopy.

Esterification reaction on ball milled jute fibers

Jute fibers $(1 \mathrm{~g})$ were pre-treated by ball milling at a rotational speed of $800 \mathrm{rpm}$ for $2 \mathrm{~min}$. Then, they were suspended in butyric anhydride $(8 \mathrm{~mL}$, $47.68 \mathrm{mmol} / \mathrm{g}$ cellulose $)$ and $\mathrm{H}_{2} \mathrm{SO}_{4} \quad(100 \mu \mathrm{L}$, $1.88 \mathrm{mmol} / \mathrm{g}$ cellulose) was added. The reaction was carried out at $110{ }^{\circ} \mathrm{C}$ for 1 (JF-B1-E1), 2 (JF-B1-E2) or 4 (JF-B1-E4) hours. After this time, the reaction was stopped and purification was carried out by multiple washings with ethanol. The formation of the ester bond was confirmed by FTIR spectroscopy.

General method to determine the degree of substitution (DS) of ester derivatives

The degree of substitution (DS) of the ester derivatives JF-B1-E1, JF-B1-E2 and JF-B1-E4 was determined by titration. The samples $(0.0700-0.0800 \mathrm{~g})$ were stirred in $70 \%$ ethanol aqueous solution $(20 \mathrm{~mL})$ for $30 \mathrm{~min}$. Then, $0.5 \mathrm{M} \mathrm{NaOH}(20 \mathrm{~mL})$ was added and the reaction was left stirring for $48 \mathrm{~h}$. After this time, the excess of $\mathrm{NaOH}$ was back titrated with $0.5 \mathrm{M} \mathrm{HCl}$ in the presence of phenolphthalein as indicator. A blank measurement was performed each time.

The DS was obtained from the following equation:

$\mathrm{DS}=(\mathrm{MAGU} \times A) /(C-A \times B)$

MAGU molecular weight of the anhydroglucose unit, $A$ molar variation before and after saponification, $B$ molecular weight of the grafted acyl residue, $C$ weight of the dry sample.

The resulting value was then used to determine the $\%$ of functionalization.

Fourier transform infrared spectroscopy (FTIR)

Fourier transform infrared spectroscopy (FTIR) was carried out for all the samples, excepting the ester derivatives, with the apparatus Thermo Scientific iS50 
FTIR spectrometer with build in diamond ATR accessory. The FTIR spectra of the ester derivatives JF-B1-E1, JF-B1-E2 and JF-B1-E4 were recorded using a Bruker Alpha FTIR spectrometer. For all measurements, the samples were directly placed in the ATR accessory. The spectra were obtained in a wavenumber range of $400-4000 \mathrm{~cm}^{-1}$, at $4 \mathrm{~cm}^{-1}$ resolution, in the absorption mode.

Hydrodynamic diameter determination

Hydrodynamic diameter determination was carried out using a Helos/BR Sympatec device in the range between 4.5 and $875 \mu \mathrm{m}$ and over water dispersions of the fibers. Each measurement was repeated three times and average values were reported.

\section{Results and discussion}

Synthesis and characterization of NCOfunctionalized jute fibers

\section{Traditional method}

Jute fibers (JF) were reacted with hexyl isocyanate in toluene, in the presence of triethylamine as catalyst, thus promoting the interaction of the - $\mathrm{NCO}$ groups of the isocyanate with the $-\mathrm{OH}$ groups of cellulose and, consequently, inserting 6-carbon chains on the surface of the cellulose fibers (Scheme 1).

Following the guidance stablished by Gallego et al. (2013b), the proportions of reagents corresponding to a functionalization degree of $5 \%$ (JF-FC) were approximately selected (assuming $100 \%$ cellulose as fiber composition), in order to respect the limits established by the current regulation on the use of isocyanates in some commercial products. The FTIR analysis (Fig. 1), however, revealed that, despite no free $-\mathrm{NCO}$ was detected (Fig. 1a), there was no evidence of urethane linkage (Fig. $1 \mathrm{~b}$ and 1c), therefore, the chemical reaction between the-OH groups of cellulose and the $-\mathrm{NCO}$ groups of the isocyanate did not occur. This may have been due to the composition of jute fibers (Moriana et al. 2014), where lignin, hemicellulose and other impurities hinder the accessibility to the hydroxyl groups for chemical modifications. For this reason, the application of a pretreatment to boost cellulose fiber reactivity was considered necessary.

Jute fibers were therefore pre-treated via mercerization. This well-known alkali treatment is usually used to increase the cellulose content by removing hemicellulose and lignin from the raw fibers and make hydroxyl groups more accessible for chemical modifications. Additionally, mercerization promotes the breakage of the hydrogen bonds producing changes in the crystallinity of the fibers structure (Borysiak and Doczekalska 2005; Jähn et al. 2002; Liu and Hu 2008). According to $\mathrm{Yu}$ et al. (2014), depending on the conditions applied for the mercerization process (i.e. concentration of the $\mathrm{NaOH}$ solution, temperature and time of alkalization), cellulose polymorphs and the crystallinity of the fibers, specifically pristine jute fibers, can be tuned. For this reason, two boundary conditions were selected for the present work: (1) conditions to obtain the highest CI and (2) conditions to obtain the lowest CI. In the first case (JF-A8), ground jute fibers were dispersed in $8 \% \mathrm{NaOH}$ aqueous solution for $4 \mathrm{~h}$ at $70{ }^{\circ} \mathrm{C}$. In the second case (JF-A15), the concentration of the $\mathrm{NaOH}$ solution was increased up to $15 \%$ and the temperature to $85{ }^{\circ} \mathrm{C}$. Both mercerized samples were then NCO-functionalized (JF-A8-FC and JF-A15-FC) reproducing exactly the previously described procedure. The FTIR spectra displayed no signal of free $-\mathrm{NCO}\left(2272 \mathrm{~cm}^{-1}\right.$, Fig. 1a), meaning that all the $-\mathrm{NCO}$ groups reacted. This time, however, clear evidence of urethane
Scheme 1 Chemical reaction between cellulose and hexyl isocyanate by the traditional method

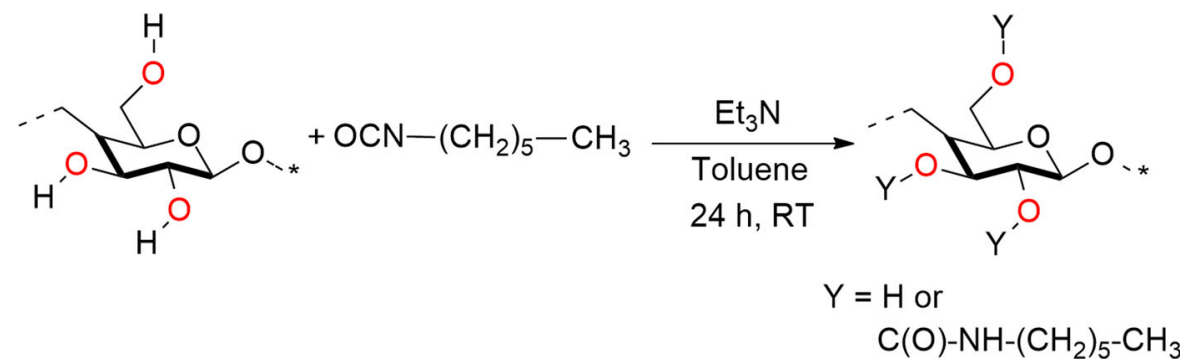




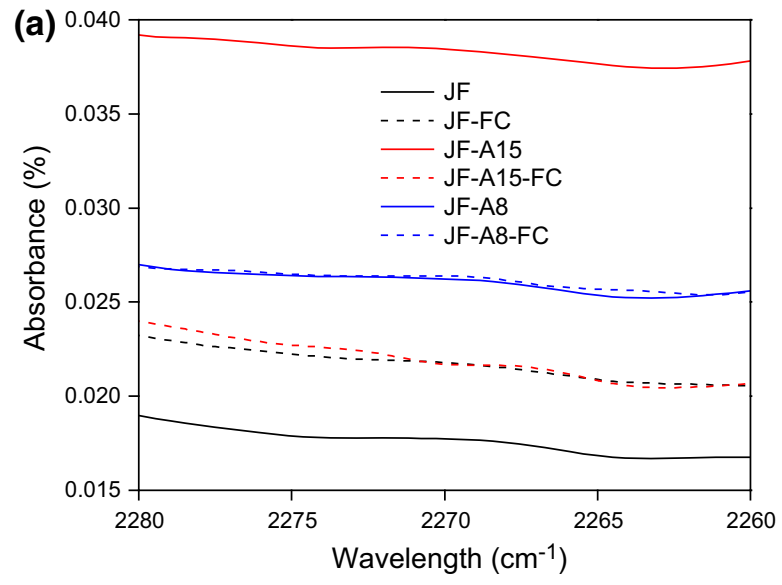

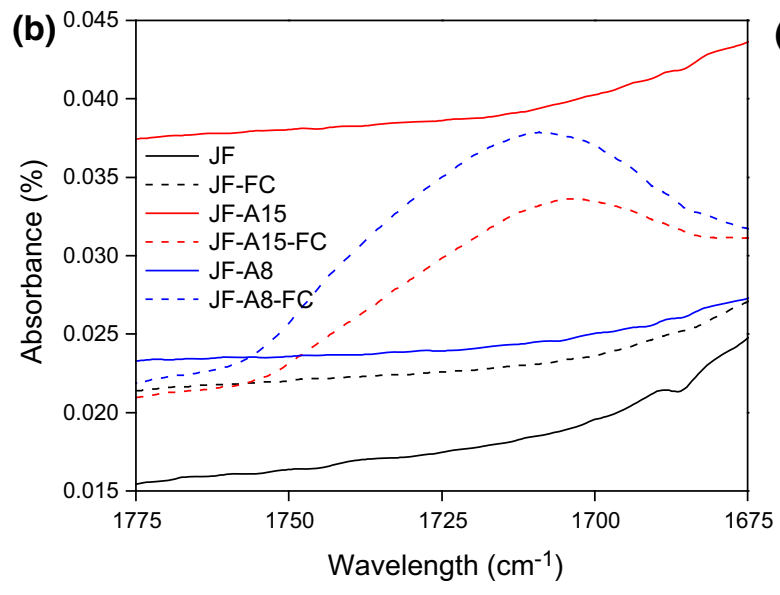

Fig. 1 FTIR spectra of the samples JF (black line), JF-A15 (red line), JF-A8 (blue line) and their corresponding NCO-functionalized derivatives (JF-FC, JF-A15-FC and JF-A8-FC) (dash

linkage, considering the low levels of modification applied, could be found for the samples that were previously mercerized, disregarding the conditions applied. In particular, the peak corresponding to the carbonyl group of the urethane linkage was detected at 1704 and $1709 \mathrm{~cm}^{-1}$ for samples JF-A15-FC and JFA8-FC, respectively (Fig. 1b). Furthermore, the signal corresponding to the amino group of the urethane linkage was also observed in the two samples at $1537 \mathrm{~cm}^{-1}$ (Fig. 1c). This confirmed that mercerization as a pre-treatment of lignocellulosic fibers, including jute fibers, needs to be performed to successfully functionalize cellulose.

Interestingly, some absorption bands can be used to investigate the structural transformation occurred in the fiber as a result of the inter- and intra-molecular bonds variations caused by the alkali treatment

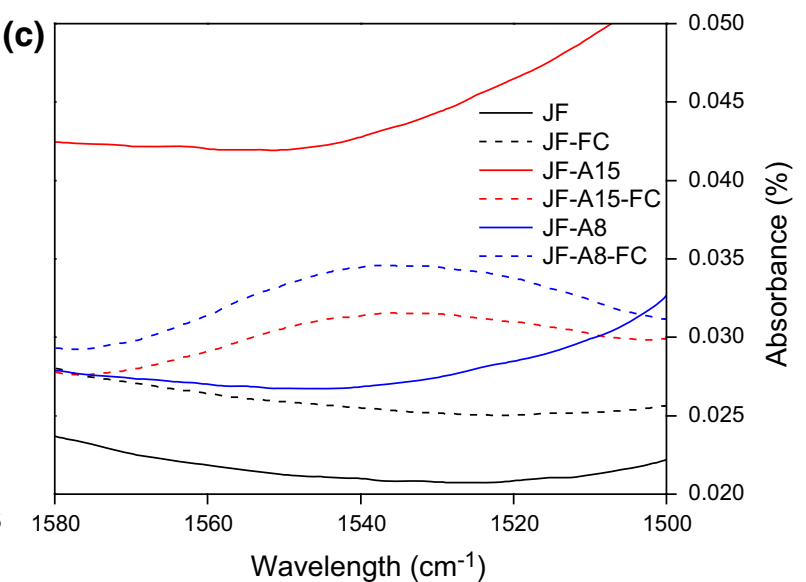

lines) focusing on the regions displaying a free -NCO groups and $\mathbf{b}$ carbonyl and $\mathbf{c}$ amino groups of the urethane linkages

applied. Thus, the signal corresponding to the $\mathrm{CH}_{2}$ stretching (3000-2800 $\mathrm{cm}^{-1}$ ) (Fig. 2a) and the signals at 1370 and $1315 \mathrm{~cm}^{-1}$ (Fig. 2b), 1160 and $1110 \mathrm{~cm}^{-1}$ (Fig. 2c) and $895 \mathrm{~cm}^{-1}$ (Fig. 2d) showed lower wavelength values for JF-A15 and JF-A15-FC in comparison to the samples that were not mercerized (JF and JF-FC) and those mercerized with $8 \% \mathrm{NaOH}$ aqueous solution (JF-A8 and JF-A8-FC). The shifting of these specific signals to lower wavelengths, evident in JF-A15 and JF-A15-FC spectra, indicates the switch from cellulose I to cellulose II and amorphous cellulose (Yu et al. 2014; Carrillo et al. 2004).

These results can be explained taking into consideration that three phases take place during the mercerization process, as described by Liu and $\mathrm{Hu}$ (2008): fiber swelling, disruption of the crystalline domains and formation of new crystalline lattice after 


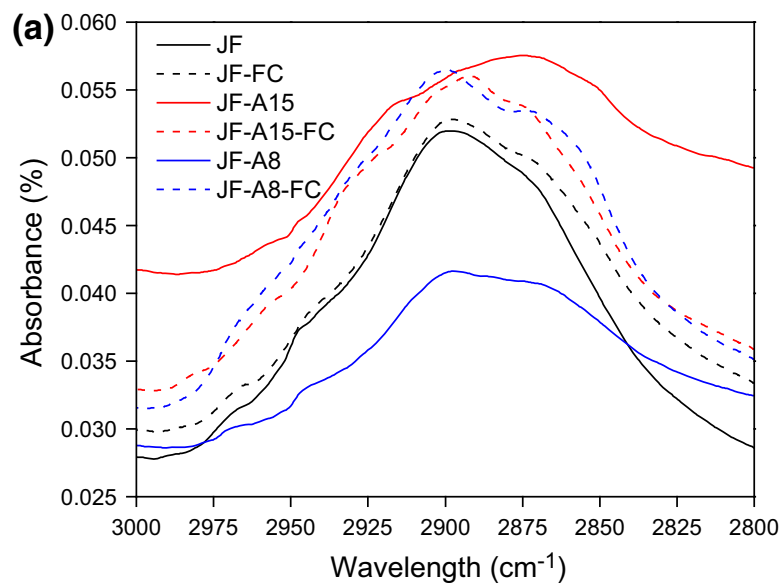

(b)
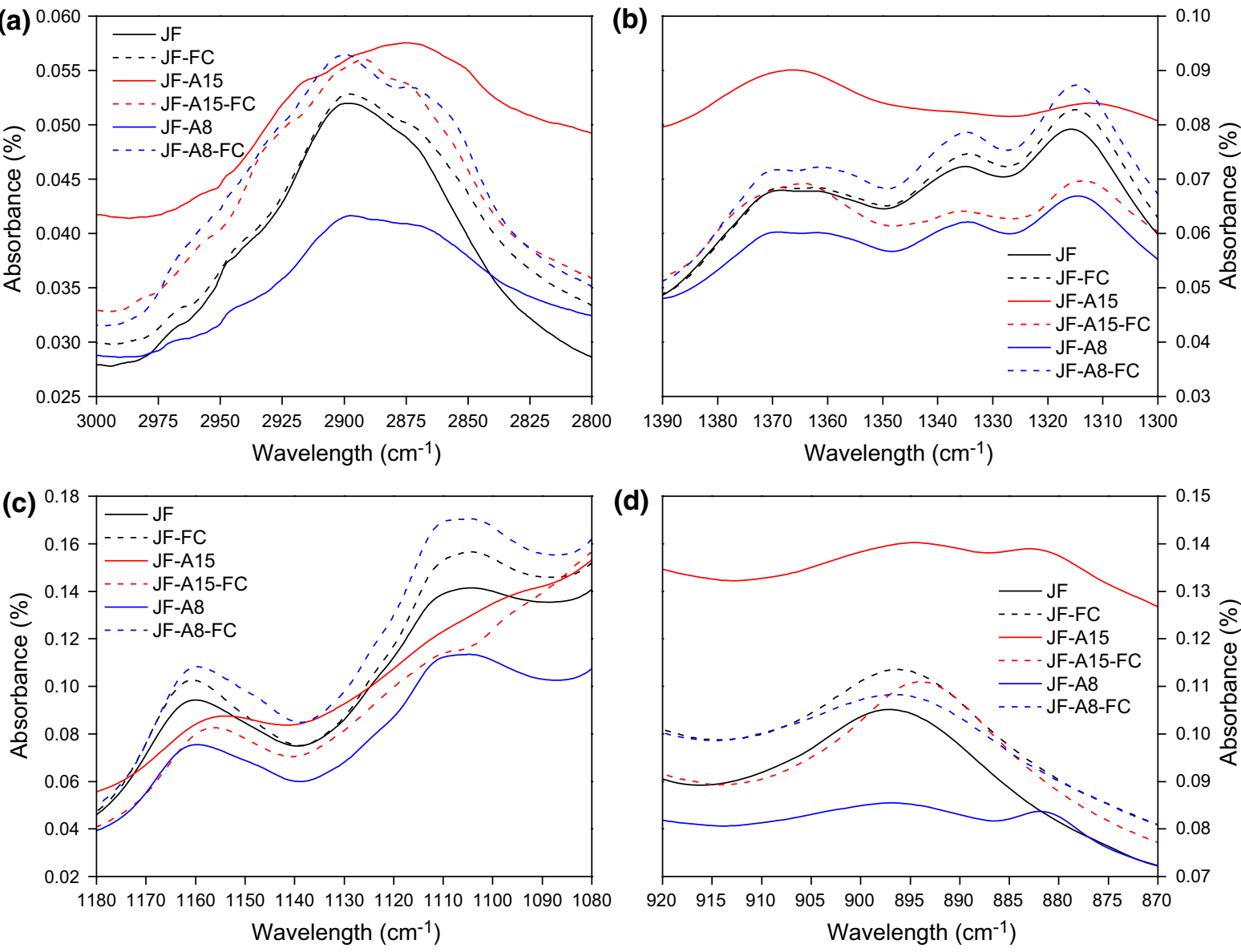

Fig. 2 FTIR spectra of the samples JF (black line), JF-A15 (red line), JF-A8 (blue line) and their corresponding NCO-functionalized derivatives (JF-FC, JF-A15-FC and JF-A8-FC) (dash

eliminating the alkali solution. At low $\mathrm{NaOH}$ concentrations (i.e. $8 \%$ ) the hydroxide ions are fully hydrated and cannot penetrate the cellulose lattice due to size restrictions. Therefore, they can only dissolve and remove lignin and other impurities, producing an increase of the CI. By contrast, at a higher $\mathrm{NaOH}$ concentration (i.e., 15\%), there is less water to hydrate the hydroxide ions, which can penetrate the cellulose lattice more easily, swelling and disrupting it, leading to an increase of the amorphous region. The transition from cellulose I to cellulose II after alkalization is confirmed by the signals observed at around $895 \mathrm{~cm}^{-1}$ (Fig. 2d), where only the mercerized jute fibers (JFA15 and JF-A8) showed two bands: one corresponding to cellulose I at 895 and $897 \mathrm{~cm}^{-1}$, respectively, and the other corresponding to cellulose II at 883 and $882 \mathrm{~cm}^{-1}$, respectively. However, the NCO-

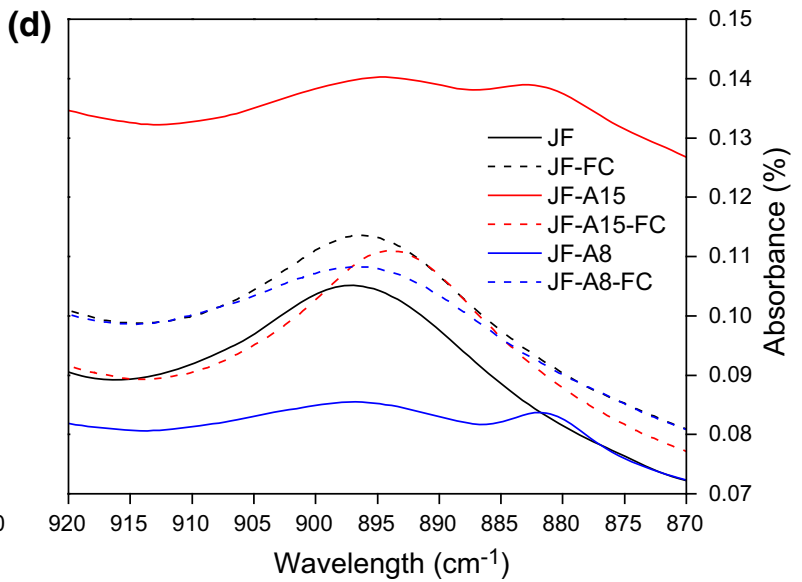

lines) focusing on the bands a 3000-2800 $\mathrm{cm}^{-1}$ b 1370 and $1310 \mathrm{~cm}^{-1}$ c 1165 and $1110 \mathrm{~cm}^{-1}$ and $\mathbf{d} 895 \mathrm{~cm}^{-1}$

functionalized derivatives did not show any cellulose II signal and only JF-A15-FC displayed a slightly shifted to lower wavelengths peak, probably due to its more amorphous character. Moreover, the bands displayed by JF-A15 appeared to be at a lower wavelength than those of the NCO-functionalized derivative (JF-A15-FC). We can therefore conclude that the insertion of the C6-chains increased the internal order of the structure providing higher crystallinity.

\section{Solvent-free method: ball milling}

To be more in line with the green-chemistry design, toluene, which was the reaction medium in the previously described method for the NCO-functionalization of jute fibers, was avoided by applying ball 
milling, a the solvent-free alternative. Different chemical modifications of cellulose by ball milling can be found in literature (Hu et al. 2015; Qin et al. 2016; Rao et al. 2015), however, the mechanically activated NCO-functionalization of cellulose fibers by ball milling has not been previously reported. This mechanical process is known to promote defibrillation of fibers and splitting into nano-fiber segments (Baheti et al. 2012b), as well as the decrease of crystallinity (Avolio et al. 2012), thus facilitating the interactions between the $-\mathrm{OH}$ groups of cellulose and the $-\mathrm{NCO}$ groups of the isocyanate. Hence, jute fibers were NCO-functionalized with hexyl isocyanate in a planetary ball mill using the same proportions of reagents as those of the traditional method (5\% NCO-functionalization). Since ball milling is based on the energy released at the point of collision between the balls and the friction of balls on the wall (Baheti et al. 2012a), the reaction was performed with and without catalyst to check if this energy was sufficient for the reaction to take place.

First of all, different rotational speeds and milling times were tested in order to identify the optimal conditions for fibers preparation and chemical modification. Subsequently, the size of these ball milled fibers was measured by dynamic light scattering in terms of hydrodynamic diameter, which corresponds to the diameter of a hypothetical sphere that displays an equivalent diffusion behavior. These measurements are commonly performed to obtain information on the dimensions of cellulose micro- and nano- fibers and cellulose nanocrystals (Beyene et al. 2018; Božič et al. 2018; Brito et al. 2012; Gaudreault et al. 2005; Sonia and Dasan 2013). As a result, when jute fibers were ball milled at $800 \mathrm{rpm}$ for 1 or $2 \mathrm{~min}$, a fine powder was obtained. On the contrary, a fluffy residue was achieved when the rotational speed was reduced to $700 \mathrm{rpm}$. At that velocity, $2 \mathrm{~min}$ were required for the fibers to become a fine powder consisting of particles that showed a monomodal distribution of hydrodynamic diameter with a value of $\mathrm{d} 50 \%$ of $13.28 \mu \mathrm{m}$ (Fig. 3 and Table 1). A powder was also obtained after 2 or $3 \mathrm{~min}$ of milling at $600 \mathrm{rpm}$, but $1 \mathrm{~min}$ was not. The laser diffraction analysis of the latter showed two main populations of particles with a hydrodynamic diameter of $84.63 \mu \mathrm{m}$ of $\mathrm{d} 50 \%$. However, as milling time increased up to $2 \mathrm{~min}$ the result was the decrease of the particle hydrodynamic diameter displaying a monomodal distribution with a value of $\mathrm{d} 50 \%$ of
$27.26 \mu \mathrm{m}$. Increasing the milling time to $3 \mathrm{~min}$ induced, once again, a reduction in the particle hydrodynamic diameter to $19.30 \mu \mathrm{m}$, as expected. Milling was then performed at $500 \mathrm{rpm}$ for 2, 4 and $5 \mathrm{~min}$ and it was only after $5 \mathrm{~min}$ of milling when a powder could be obtained, showing a monomodal distribution of the particles with a hydrodynamic diameter of $23.10 \mu \mathrm{m}$ of $\mathrm{d} 50 \%$. When the rotational speed was reduced to $400 \mathrm{rpm}, 10 \mathrm{~min}$ of milling were needed to achieve a powder, whereas a fluffy residue was obtained after 2, 3, 4 and $5 \mathrm{~min}$. The particles isolated after 10 min milling showed a monomodal distribution with a hydrodynamic diameter with a value of $\mathrm{d} 50 \%$ of $21.17 \mu \mathrm{m}$. The resulting average hydrodynamic diameters, which are in the range of d50\% between $13.28 \mu \mathrm{m}$ and $84.63 \mu \mathrm{m}$, depending on the applied milling treatment, are comparable to the values reported in literature for activated jute fibers (Alves Fidelis et al. 2013; Liu and Dai 2007; Peponi et al. 2008; Rathore and Pradhan 2017). From this study can be extracted that higher rotational speeds and longer milling times produce smaller hydrodynamic diameters. So that, to make sure that jute fibers were ground enough to be reactive, the conditions that were chosen to prepare the fibers and conduct the reactions were $800 \mathrm{rpm}$ rotational speed for $2 \mathrm{~min}$ of ball milling.

The NCO-functionalization reaction was initially carried out directly in the ball mill applying the previously selected conditions and avoiding premilling of the jute fibers. In this case, cellulose fibers, hexyl isocyanate and catalyst were milled together at $800 \mathrm{rpm}$ for 2 min providing JF-B1-FC as product. The same process was also performed in the absence of catalyst to give JF-B1-F. Unfortunately, both products were heterogeneous aggregates of ground jute fibers with black spots (Fig. $4 \mathrm{~b}$ and $4 \mathrm{c}$ ). For this reason, a pre-milling treatment was considered necessary for the activation and homogeneous reaction of the fibers. When jute fibers were submitted to ball milling for $2 \mathrm{~min}$ at $800 \mathrm{rpm}$ prior to the reaction and then ball milled again together with hexyl isocyanate, in absence (JF-B2-F) and presence of the catalyst (JFB2-FC), for another $2 \mathrm{~min}$ at the same rotational speed, a homogeneous fine powder was obtained (Fig. 4d and 4e). The products were further characterized via FTIR (Fig. 5) and compared to nonfunctionalized ball-milled ground jute fibers (JF-B) to check if the NCO-functionalization was 
Fig. 3 Hydrodynamic diameter measurements by laser diffraction of jute fibers ball milled at: $700 \mathrm{rpm}-2 \mathrm{~min}$ (red line), $600 \mathrm{rpm}-3 \mathrm{~min}$ (purple line), $600 \mathrm{rpm}-2 \mathrm{~min}$ (blue line), $600 \mathrm{rpm}-1 \mathrm{~min}$ (orange line), $500 \mathrm{rpm}-$ 5 min (black line), $400 \mathrm{rpm}-10 \mathrm{~min}$ (green line)

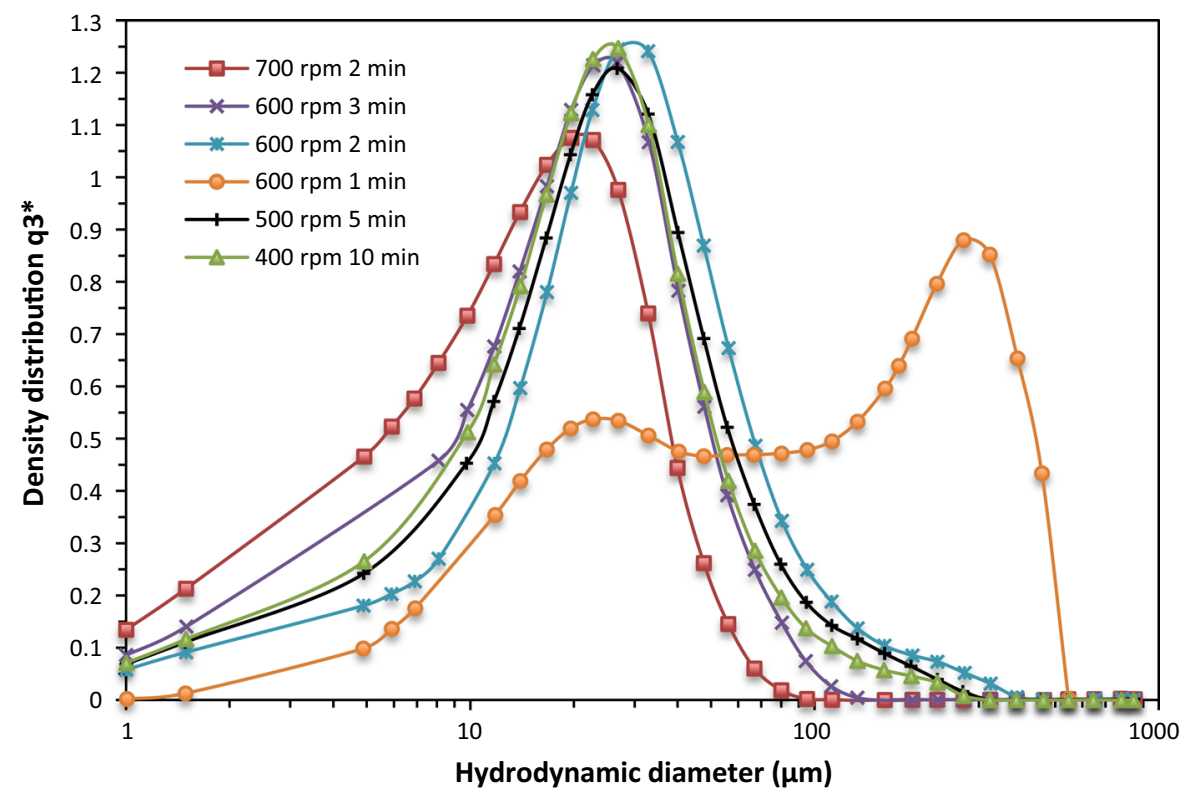

Table 1 Hydrodynamic diameter measurements

\begin{tabular}{|c|c|c|c|c|c|}
\hline \multicolumn{2}{|c|}{ Ball mill treatment } & \multicolumn{4}{|c|}{ Hydrodynamic diameters } \\
\hline $\begin{array}{l}\text { Rotational speed } \\
\text { (rpm) }\end{array}$ & $\begin{array}{l}\text { Milling time } \\
(\min )\end{array}$ & $\begin{array}{l}\mathrm{d} 50 \% \\
(\mu \mathrm{m})\end{array}$ & $\begin{array}{l}\mathrm{d} 10 \% \\
(\mu \mathrm{m})\end{array}$ & $\begin{array}{l}\mathrm{d} 90 \% \\
(\mu \mathrm{m})\end{array}$ & SPAN \\
\hline 700 & 2 & $13.28 \pm 0.14$ & $2.48 \pm 0.01$ & $34.24 \pm 0.08$ & 2.40 \\
\hline 600 & 3 & $19.30 \pm 0.14$ & $3.52 \pm 0.01$ & $45.97 \pm 0.35$ & 2.20 \\
\hline 600 & 2 & $27.26 \pm 0.56$ & $5.41 \pm 0.04$ & $73.08 \pm 0.68$ & 2.48 \\
\hline 600 & 1 & $84.63 \pm 5.05$ & $12.47 \pm 0.18$ & $347.82 \pm 5.95$ & 3.97 \\
\hline 500 & 5 & $23.10 \pm 0.22$ & $4.30 \pm 0.01$ & $62.09 \pm 0.08$ & 2.50 \\
\hline 400 & 10 & $21.17 \pm 0.24$ & $4.14 \pm 0.01$ & $53.39 \pm 0.31$ & 2.32 \\
\hline
\end{tabular}

(a)

(b)

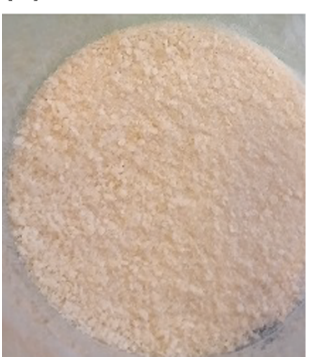

(c)

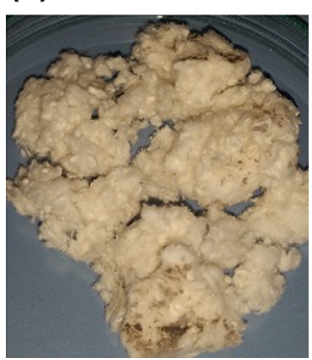

(d)

(e)

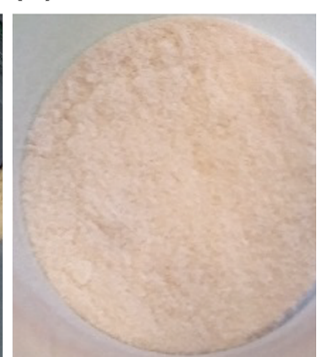

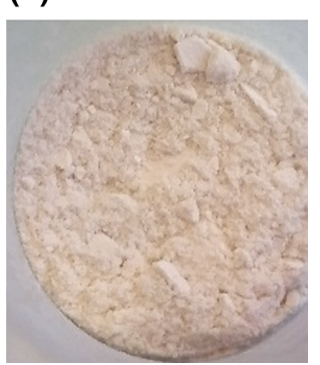

Fig. 4 Physical appearance of a JF-B, b JF-B1-F, c JF-B1-FC, d JF-B2-F and e JF-B2-FC

successfully achieved. Due to the high reactivity of isocyanate groups and the low quantity employed in the reaction, the signal corresponding to the free NCO functionality, which usually appears at $2272 \mathrm{~cm}^{-1}$, was not observed (Fig. 5c), meaning that the isocyanate groups reacted completely. Moreover, the formation of urethane linkages was evident for both products obtained with (JF-B2-FC) or without catalyst (JF-B2-F), and no significant differences between them were observed. 

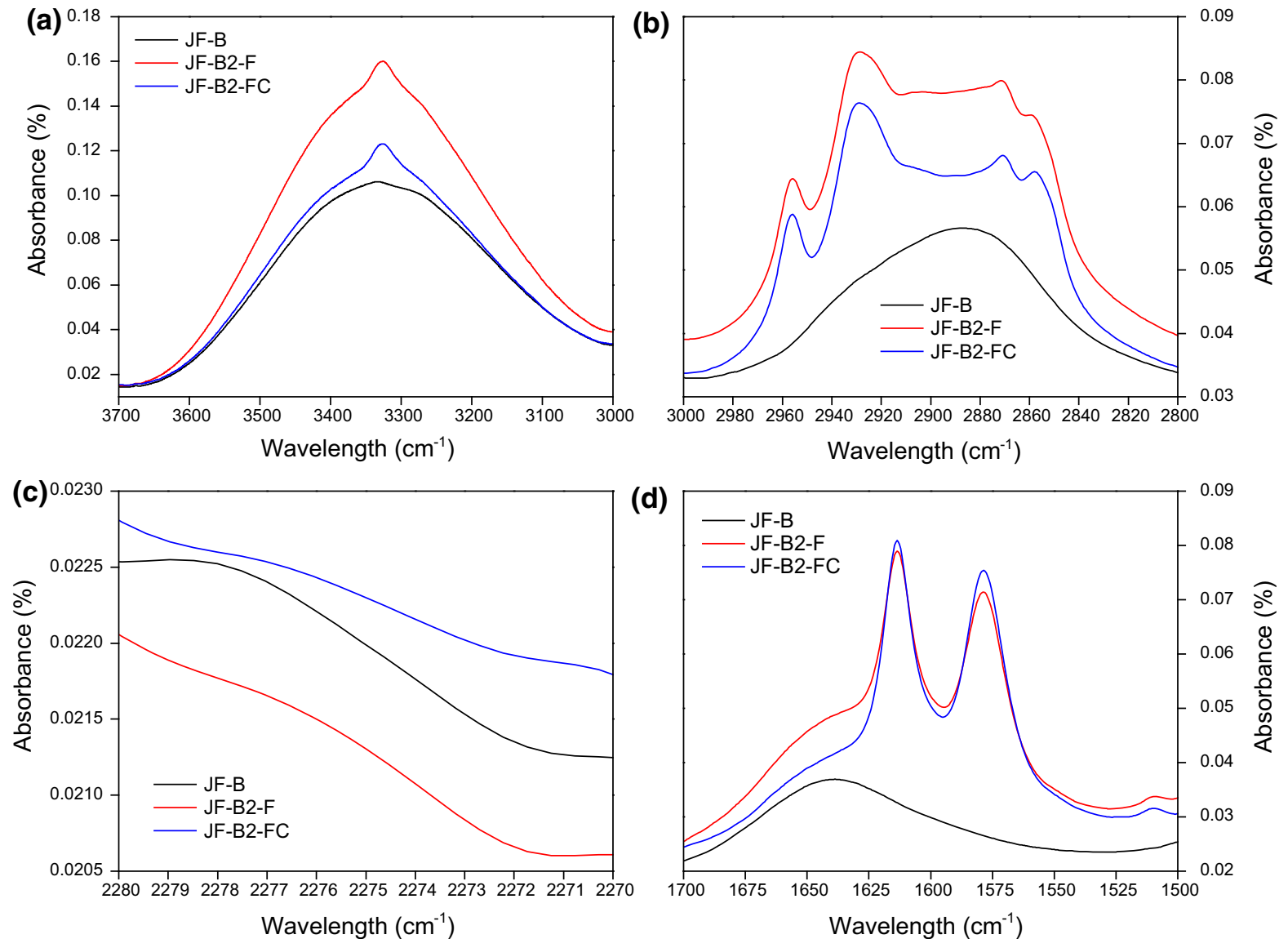

Fig. 5 FTIR spectra of the samples JF-B (black line), JF-B2-F (red line), JF-B2-FC (blue line) focusing on the regions displaying a hydroxyl and amino groups, $\mathbf{b}$ ethylene group, $\mathbf{c}$ free $-\mathrm{NCO}$ groups and $\mathbf{d}$ carbonyl and amino groups of the urethane linkages

The signal corresponding to the $\mathrm{N}-\mathrm{H}$ vibration, displayed at around $3330 \mathrm{~cm}^{-1}$, was observed for both samples JF-B2-F and JF-B2-FC, but not in the spectrum of the non-functionalized reference JF-B (Fig. 5a). More defined and intense signals corresponding to the $\mathrm{C}-\mathrm{H}$ linkages $\left(3000-2800 \mathrm{~cm}^{-1}\right.$ ) appeared in the NCO-functionalized samples due to the alkyl chain of hexyl isocyanate (Fig. 5b). Other visible signals that were identified in the chemically modified fibers (Fig. 5d) include a band corresponding to $\mathrm{C}=\mathrm{O}$ group of the carbonyl group present in the urethane linkage $\left(1614 \mathrm{~cm}^{-1}\right)$. This band shifted to lower wavelength than expected due to hydrogen bonding. The vibration of $\mathrm{N}-\mathrm{H}$ of the amide group of the urethane linkage was also identified at 1578 and $1509 \mathrm{~cm}^{-1}$. Presuming 100\% conversion and considering the high probability of -NCO groups reacting with - $\mathrm{OH}$ groups of cellulose, the final functionalization degree must be close to $5 \%$, as purposed.

In summary, the chemical modification of cellulose fibers from jute with hexyl isocyanate in a solvent-free method using a planetary ball mill was successfully carried out. Furthermore, the reaction outcomes demonstrated that the use of catalyst can be avoided, since the energy produced during the ball milling process was sufficient to allow the chemical reaction to occur. In view of these advantages, NCO-functionalized materials synthetized through ball milling deserve to be further investigated and more in deep characterized to better understand the impact of ball milling on their properties and thus discover potential applications. Although recent research on similar systems may give some ideas about the effect of ball milling on fibers characteristics. For instance, Ling et al. (2019) explored the effect of a vibratory ball mill, 
at a filling ratio of $50 \%$, run at $1750 \mathrm{rpm}$ for 15-120 min, on cotton cellulose. As a result, ball milled fibers experimented the steadily decrease of molecular weight and average size with time, what was also observed in ball milled jute fibers, although more moderately regarding the less aggressive milling conditions. On the contrary, specific surface area increased, which, together with the increase of the amorphous fraction with milling time, would partly explain the enhancement of fibers reactivity. Additionally, thermal analysis revealed reduced stability of ball milled fibers related to the constant heating suffered during ball milling and the reduction in fibers size. Conversely, improved thermal stability was found for NCO-functionalized lignocellulosic pulps in previous research of our group (Gallego et al. 2015). So that, the chemical modification of cellulose fibers with -NCO groups should counteract the impact of ball milling on thermal stability of cellulose fibers.

\section{Esterification of ball milled jute fibers}

Ball milled jute fibers were also reacted with butyric anhydride in the presence of $\mathrm{H}_{2} \mathrm{SO}_{4}$ at $110{ }^{\circ} \mathrm{C}$ for 1,2 or $4 \mathrm{~h}$ to obtain the corresponding ester derivatives with different degrees of functionalization depending on the reaction time (Scheme 2). With the aim of stimulating the reactivity of jute fibers, as previously performed with the NCO-functionalization reaction, fibers were pre-treated by ball milling at $800 \mathrm{rpm}$ for 2 min to obtain an activated powder that was subsequently esterified in a reactor. The application of different esterification times led to products with different DS values. In particular, when the reaction was carried out for $1 \mathrm{~h}$ (JF-B1-E1) a DS of 0.47 , corresponding to a $15.7 \%$ functionalization, was achieved. When the reaction time was prolonged to $2 \mathrm{~h}$ (JF-B1-E2), the DS increased up to 0.85 (28.4\% functionalization). The ester content further increased when the reaction was performed for $4 \mathrm{~h}$ (JF-B1-E4), providing a value of DS of 2.14 (71.3\% functionalization). Thus, longer reactions times provided higher esterification degrees.

The success of the esterification of the activated jute fibers was confirmed by FTIR, which showed the characteristic stretching band of the ester carbonyl group at $1739-1749 \mathrm{~cm}^{-1}$ (Fig. 6). This band is not visible for the corresponding unsubstituted derivative (JF-B) and its intensity increases proportionally with the amount of ester present in each compound. The other characteristic bands for cellulose derivatives appeared at $3300 \mathrm{~cm}^{-1}$ (-OH vibration) and 2890-2910 $\mathrm{cm}^{-1}$ (-CH stretching). The $\mathrm{OH}$ vibration bands decreased in intensity for the derivative containing the higher percentage of functionalization. The $-\mathrm{CH}_{2}$ and $-\mathrm{CH}_{3}$ vibration signals and the $-\mathrm{C}-\mathrm{O}-\mathrm{C}-$ stretching bands were also visible in the region between 1000 and $1500 \mathrm{~cm}^{-1}$.

Once again, the application of ball milling as a tool for the activation of the reactivity of cellulose fibers was successful: ball mill-activated jute fibers were effectively esterified in a reactor and the functionalization degree was modulated by varying the reaction time. Therefore, jute fibers became reactive enough just with the preliminary ball milling activation treatment, being able to undergo the esterification reaction without needing to apply in situ the ball milling process.

\section{Conclusions}

We conclude that ball milling is an efficient technology that can be successfully used to activate and functionalize cellulose fibers. Jute fibers were successfully activated through ball milling and subsequently functionalized by $\mathrm{NCO}$-functionalization and esterification. In the case of the NCO-
Scheme 2 Esterification reaction performed on ball milled jute fibers

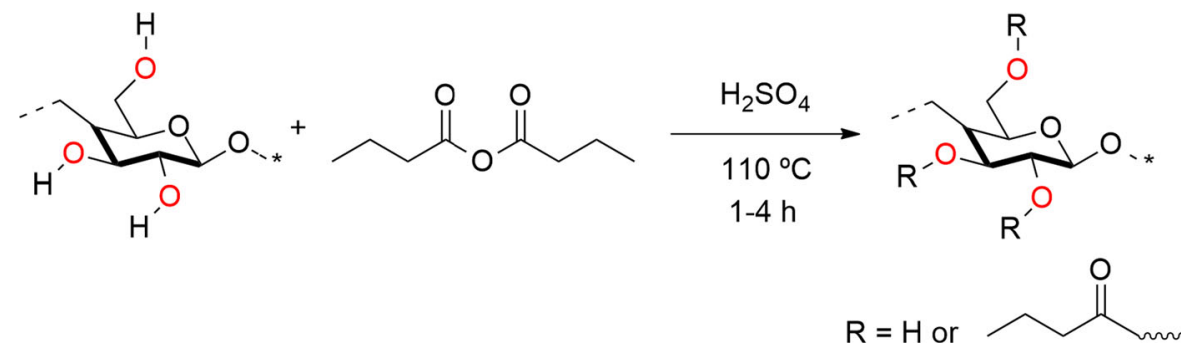


Fig. 6 FTIR spectra of the samples JF-B (purple line), JF-B1-E1 (green line), JFB1-E2 (red line) and JF-B1E4 (blue line), obtained by the esterification reaction of ball milled jute fibers

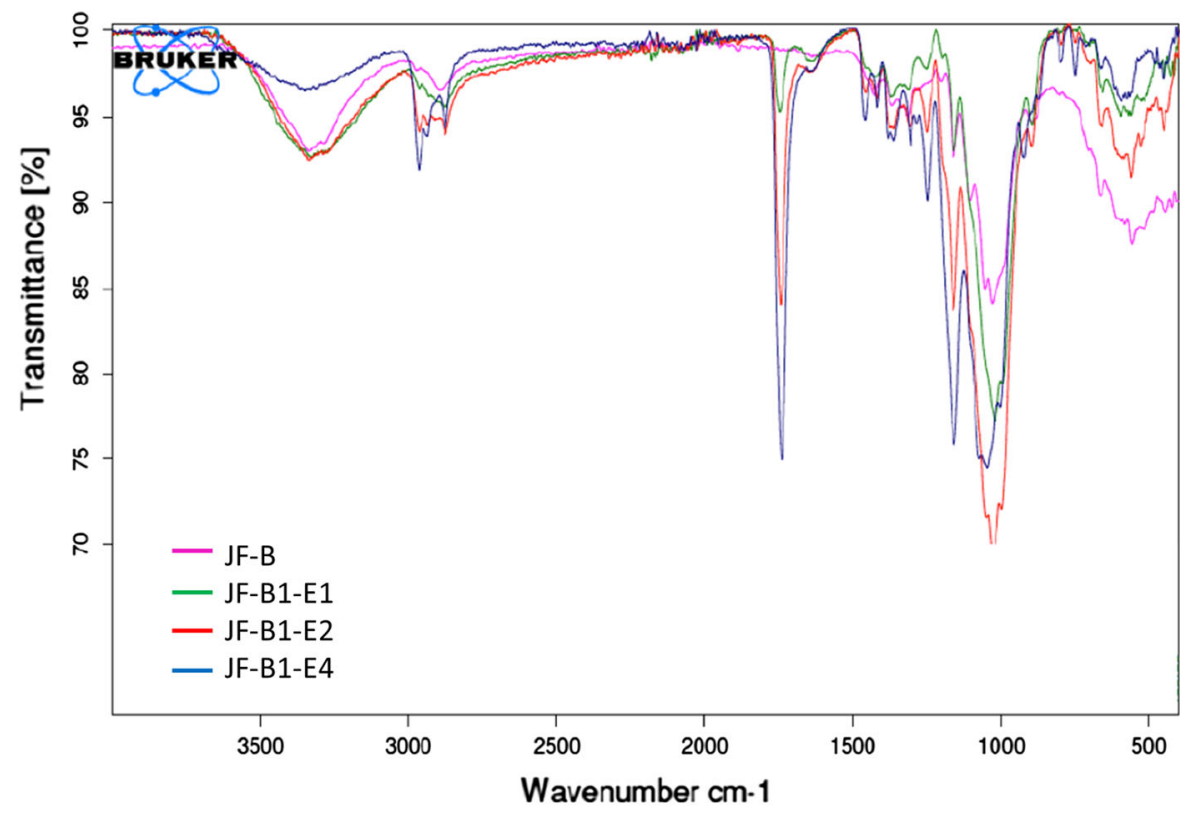

functionalization reaction, jute fibers were not only activated, but also chemically modified in the ball mill setup. Consequently, this approach allowed avoiding the use of toluene as solvent and the basic catalyst employed in the traditional method described, thus reducing the reaction costs and being more in line with the green chemistry design. To the best of our knowledge this is the first time that this type of functionalization is conducted using a ball mill. Compared to traditional methods described in literature this method has several advantages including speed, cost-effectiveness and environmental friendliness.

Acknowledgments This work is part of the research project Intelligent Structuring Systems for Complex Flowing Products sponsored by the European Union's Seventh Framework Program for research, technological development and demonstration under Grant Agreement no. 612330. The authors gratefully acknowledge its financial support. The authors also acknowledge the support of Celesa for jute fibers samples supply, and Steff Van Loy and the department of Chemical Engineering of KU Leuven for the use of the ball mill.

\section{References}

Ago M, Endo T, Hirotsu T (2004) Crystalline transformation of native cellulose from cellulose I to cellulose ID polymorph by a ball-milling method with a specific amount of water.
Cellulose 11(2):163-167. https://doi.org/10.1023/B: CELL.0000025423.32330.fa

Ago M, Endo T, Okajima K (2007) Effect of solvent on morphological and structural change of cellulose under ballmilling. Polym J 39:435. https://doi.org/10.1295/polymj. PJ2006096

Alves Fidelis ME, Castro Pereira TV, Martins Gomes OdF, de Andrade Silva F, Toledo Filho RD (2013) The effect of fiber morphology on the tensile strength of natural fibers. J Mater Res Technol 2(2):149-157. https://doi.org/10. 1016/j.jmrt.2013.02.003

Arrakhiz FZ, Elachaby M, Bouhfid R, Vaudreuil S, Essassi M, Qaiss A (2012) Mechanical and thermal properties of polypropylene reinforced with alfa fiber under different chemical treatment. Mater Des 35:318-322. https://doi. org/10.1016/j.matdes.2011.09.023

Avolio R, Bonadies I, Capitani D, Errico ME, Gentile G, Avella M (2012) A multitechnique approach to assess the effect of ball milling on cellulose. Carbohydr Polym 87(1):265-273. https://doi.org/10.1016/j.carbpol.2011.07.047

Baheti V, Abbasi R, Militky J (2012a) Ball milling of jute fibre wastes to prepare nanocellulose. World J Eng 9(1):45-50. https://doi.org/10.1260/1708-5284.9.1.45

Baheti V, Marsalkova M, Rehan A, Militký J (2012b) Comparison of wet milling action for fibrous and solid materials. Fibres Text 19:3-7

Beyene D, Chae M, Dai J, Danumah C, Tosto F, Demesa AG, Bressler DC (2018) Characterization of cellulase-treated fibers and resulting cellulose nanocrystals generated through acid hydrolysis. Materials 11(8):1272. https://doi. org/10.3390/ma11081272

Boerjan W, Ralph J, Baucher M (2003) Lignin biosynthesis. Annu Rev Plant Biol 54:519-546

Borysiak S, Doczekalska B (2005) X-ray diffraction study of pine wood treated with $\mathrm{NaOH}$. Fibers Text East Eur 13(5):87-89 
Božič M, Elschner T, Tkaučič D, Bračič M, Hribernik S, Kleinschek KS, Kargl R (2018) Effect of different surface active polysaccharide derivatives on the formation of ethyl cellulose particles by the emulsion-solvent evaporation method. Cellulose 25(12):6901-6922. https://doi.org/10. 1007/s10570-018-2062-2

Brito BSL, Pereira FV, Putaux JL, Jean B (2012) Preparation, morphology and structure of cellulose nanocrystals from bamboo fibers. Cellulose 19(5):1527-1536. https://doi.org/ 10.1007/s10570-012-9738-9

Cao X, Ding B, Yu J, Al-Deyab SS (2012) Cellulose nanowhiskers extracted from TEMPO-oxidized jute fibers. Carbohydr Polym 90(2):1075-1080. https://doi.org/10. 1016/j.carbpol.2012.06.046

Carrillo F, Colom X, Suñol JJ, Saurina J (2004) Structural FTIR analysis and thermal characterisation of lyocell and viscose-type fibres. Eur Polym J 40(9):2229-2234. https://doi. org/10.1016/j.eurpolymj.2004.05.003

Diop CIK, Tajvidi M, Bilodeau MA, Bousfield DW, Hunt JF (2017) Evaluation of the incorporation of lignocellulose nanofibrils as sustainable adhesive replacement in medium density fiberboards. Ind Crop Prod 109:27-36. https://doi. org/10.1016/j.indcrop.2017.08.004

Dutta S, Kim J, Ide Y, Kim JH, Hossain MSA, Bando Y, Yamauchi Y, Wu KCW (2017) 3D network of cellulosebased energy storage devices and related emerging applications. Mater Horiz 4:522-545. https://doi.org/10.1039/ c6mh00500d

Gallego R, Arteaga JF, Valencia C, Franco JM (2013a) Chemical modification of methyl cellulose with HMDI to modulate the thickening properties in castor oil. Cellulose 20(1):495-507. https://doi.org/10.1007/s10570-012-98034

Gallego R, Arteaga JF, Valencia C, Franco JM (2013b) Rheology and thermal degradation of isocyanate-functionalized methyl cellulose-based oleogels. Carbohydr Polym 98(1):152-160. https://doi.org/10.1016/j.carbpol.2013.04. 104

Gallego R, Arteaga JF, Valencia C, Díaz MJ, Franco JM (2015) Gel-like dispersions of hmdi-cross-linked lignocellulosic materials in castor oil: toward completely renewable lubricating grease formulations. ACS Sustain Chem Eng 3(9):2130-2141. https://doi.org/10.1021/acssuschemeng. 5 b00389

Gaudreault R, Van de Ven TGM, Whitehead MA (2005) Mechanisms of flocculation with poly(ethylene oxide) and novel cofactors. Colloid Surf A 268(1):131-146. https:// doi.org/10.1016/j.colsurfa.2005.04.044

Ghali L, Aloui M, Zidi M, Bendaly H, M'Sahli S, Sakli F (2011) Effect of chemical modification of luffa cylindrica fibers on the mechanical and hygrothermal behaviours of polyester/ luffa composites. BioResources 6(4):3836-3849

Gong J, Li J, Xu J, Xiang Z, Mo L (2017) Research on cellulose nanocrystals produced from cellulose sources with various polymorphs. RSC Adv 7(53):33486-33493. https://doi. org/10.1039/C7RA06222B

Gorrasi G, Sorrentino A (2015) Mechanical milling as a technology to produce structural and functional bio-nanocomposites. Green Chem 17(5):2610-2625. https://doi.org/10. 1039/C5GC00029G
Hansen CM, Björkman A (1998) The ultrastructure of wood from a solubility parameter point of view. Holzforschung 52(4):335-344. https://doi.org/10.1515/hfsg.1998.52.4. 335

Hideno A (2016) Comparison of the thermal degradation properties of crystalline and amorphous cellulose, as well as treated lignocellulosic biomass. BioResources 11(3):6309-6319. https://doi.org/10.15376/biores.11.3. 6309-6319

Hu H, Li H, Zhang Y, Chen Y, Huang Z, Huang A, Zhu Y, Qin X, Lin B (2015) Green mechanical activation-assisted solid phase synthesis of cellulose esters using a co-reactant: effect of chain length of fatty acids on reaction efficiency and structure properties of products. RSC Adv 5(27):20656-20662. C5RA02393A

Huang G, Wang P (2017) Effects of preparation conditions on properties of rigid polyurethane foam composites based on liquefied bagasse and jute fibre. Polym Test 60:266-273. https://doi.org/10.1016/j.polymertesting.2017.04.006

Jähn A, Schröder MW, Füting M, Schenzel K, Diepenbrock W (2002) Characterization of alkali treated flax fibres by means of FT Raman spectroscopy and environmental scanning electron microscopy. Spectrochim Acta A 58(10):2271-2279. https://doi.org/10.1016/S13861425(01)00697-7

Khan AS, Man Z, Bustam MA, Kait CF, Khan MI, Muhammad N, Nasrullah A, Ullah Z, Ahmad P (2016) Impact of ballmilling pretreatment on pyrolysis behavior and kinetics of crystalline cellulose. Waste Biomass Valoris 7(3):571-581. https://doi.org/10.1007/s12649-015-9460-6

Kim JT, Netravali AN (2010) Mercerization of sisal fibers: effect of tension on mechanical properties of sisal fiber and fiber-reinforced composites. Compos Part A Appl S 41(9):1245-1252. https://doi.org/10.1016/j.compositesa. 2010.05.007

Ling Z, Wang T, Makarem M, Santiago Cintrón M, Cheng HN, Kang X, Bacher M, Potthast A, Rosenau T, King H, Delhom CD, Nam S, Edwards JV, Kim SH, Xu F, French AD (2019) Effects of ball milling on the structure of cotton cellulose. Cellulose 26(1):305-328. https://doi.org/10. 1007/s10570-018-02230-x

Liu XY, Dai GC (2007) Surface modification and micromechanical properties of jute fiber mat reinforced polypropylene composites. Express Polym Lett 1(5):299-307. https://doi.org/10.3144/expresspolymlett. 2007.43

Liu Y, Hu H (2008) X-ray diffraction study of bamboo fibers treated with $\mathrm{NaOH}$. Fiber Polym 9(6):735-739. https://doi. org/10.1007/s12221-008-0115-0

López Durán V, Larsson PA, Wågberg L (2018) Chemical modification of cellulose-rich fibres to clarify the influence of the chemical structure on the physical and mechanical properties of cellulose fibres and thereof made sheets. Carbohydr Polym 182:1-7. https://doi.org/10.1016/j. carbpol.2017.11.006

M'Hamed MO (2015) Ball milling for heterocyclic compounds synthesis in green chemistry: a review. Synth Commun 45(22):2511-2528. https://doi.org/10.1080/00397911. 2015.1058396 
Moosakazemi F, Tavakoli Mohammadi MR, Mohseni M, Karamoozian M, Zakeri M (2017) Effect of design and operational parameters on particle morphology in ball mills. Int J Miner Process 165:41-49. https://doi.org/10.1016/j. minpro.2017.06.001

Moriana R, Vilaplana F, Karlsson S, Ribes A (2014) Correlation of chemical, structural and thermal properties of natural fibres for their sustainable exploitation. Carbohydr Polym 112:422-431. https://doi.org/10.1016/j.carbpol.2014.06. 009

Nemoto S, Ueno T, Watthanaphanit A, Hieda J, Saito N (2017) Crystallinity and surface state of cellulose in wet ballmilling process. J Appl Polym Sci 134(22):44903. https:// doi.org/10.1002/app.44903

O'Sullivan AC (1997) Cellulose: the structure slowly unravels. Cellulose 4(3):173-207. https://doi.org/10.1023/A: 1018431705579

Panshin AJ, De Zeeuw C (1980) Textbook of wood technology: structure, identification, properties, and uses of the commercial woods of the United States and Canada. McGrawHill, New York

Paquet O, Krouit M, Bras J, Thielemans W, Belgacem MN (2010) Surface modification of cellulose by PCL grafts. Acta Mater 58(3):792-801. https://doi.org/10.1016/j. actamat.2009.09.057

Peponi L, Biagiotti J, Torre L, Kenny JM, Mondragòn I (2008) Statistical analysis of the mechanical properties of natural fibers and their composite materials I. Natural fibers. Polym Compos 29(3):313-320. https://doi.org/10.1002/pc. 20408

Piras CC, Fernández-Prieto S, De Borggraeve WM (2019) Ball milling: a green technology for the preparation and functionalisation of nanocellulose derivatives. Nanoscale Adv. https://doi.org/10.1039/C8NA00238J

Qin X, Zhou J, Huang A, Guan J, Zhang Q, Huang Z, Hu H, Zhang Y, Yang M, Wu J, Qina Y, Feng Z (2016) A green technology for the synthesis of cellulose succinate for efficient adsorption of $\mathrm{Cd}(\mathrm{ii})$ and $\mathrm{Pb}$ (ii) ions. RSC $\mathrm{Adv}$ 6(32):26817-26825. https://doi.org/10.1039/ C5RA27280G

Rao X, Kuga S, Wu M, Huang Y (2015) Influence of solvent polarity on surface-fluorination of cellulose nanofiber by ball milling. Cellulose 22(4):2341-2348. https://doi.org/ 10.1007/s10570-015-0659-2

Rathore A, Pradhan MK (2017) hybrid cellulose bionanocomposites from banana and jute fibre: a review of preparation, properties and applications. Mater Today Proc 4(2):3942-3951. https://doi.org/10.1016/j.matpr.2017.02. 294

Ray D, Sarkar BK, Rana AK, Bose NR (2001) Effect of alkali treated jute fibres on composite properties. B Mater Sci 24(2):129-135. https://doi.org/10.1007/BF02710089

Sonia A, Dasan KP (2013) Chemical, morphology and thermal evaluation of cellulose microfibers obtained from Hibiscus sabdariffa. Carbohydr Polym 92(1):668-674. https://doi. org/10.1016/j.carbpol.2012.09.015

Stolle A (2015) Technical implications of organic syntheses in ball mills. In: Stolle A, Ranu B (eds) Ball milling towards green synthesis: applications, projects, challenges. The Royal Society of Chemistry, London, pp 241-276. https:// doi.org/10.1039/9781782621980-00241

Stolle A, Szuppa T, Leonhardt SES, Ondruschka B (2011) Ball milling in organic synthesis: solutions and challenges. Chem Soc Rev 40(5):2317-2329. https://doi.org/10.1039/ C0CS00195C

Stolle A, Hopfe W, Simon W (2013) Planetary ball mills as innovative reactors in organic synthesis laboratory. Chem Ing Tech 85(6):914-918. https://doi.org/10.1002/cite. 201200087

Suwanruji P, Tuechart T, Smitthipong W, Chollakup R (2017) Modification of pineapple leaf fiber surfaces with silane and isocyanate for reinforcing thermoplastic. J Thermoplast Compos 30(10):1344-1360. https://doi.org/10.1177/ 0892705716632860

Takacs L (2002) Self-sustaining reactions induced by ball milling. Prog Mater Sci 47(4):355-414. https://doi.org/10. 1016/S0079-6425(01)00002-0

Tenorio-Alfonso A, Sánchez MC, Franco JM (2017) Preparation, characterization and mechanical properties of biobased polyurethane adhesives from isocyanate-functionalized cellulose acetate and castor oil for bonding wood. Polym Basel 9(4):132. https://doi.org/10.3390/ polym 9040132

Tonoli GHD, Mendes RF, Siqueira G, Bras J, Belgacem MN, Savastano H Jr (2013) Isocyanate-treated cellulose pulp and its effect on the alkali resistance and performance of fiber cement composites. Holzforschung 67(8):853-861. https://doi.org/10.1515/hf-2012-0195

Torres FG, Cubillas ML (2005) Study of the interfacial properties of natural fibre reinforced polyethylene. Polym Test 24(6):694-698. https://doi.org/10.1016/j.polymertesting. 2005.05.004

Voisin H, Bergström L, Liu P, Mathew AP (2017) Nanocellulose-based materials for water purification. Nanomater Basel 7(3):57. https://doi.org/10.3390/nano7030057

Yu L, Lin J, Tian F, Li X, Bian F, Wang J (2014) Cellulose nanofibrils generated from jute fibers with tunable polymorphs and crystallinity. J Mater Chem A 2(18):6402-6411. https://doi.org/10.1039/c4ta00004h

Zhang X, Do MD, Kurniawan L, Qiao GG (2010) Wheat glutenbased renewable and biodegradable polymer materials with enhanced hydrophobicity by using epoxidized soybean oil as a modifier. Carbohydr Res 345(15):2174-2182. https://doi.org/10.1016/j.carres.2010.07.020 